\title{
INVESTIGATION OF THE SWASH ZONE EVOLUTION AT WAVE TIME SCALE
}

\begin{abstract}
Jessica Astier ${ }^{1,2}$, Dominique Astruc ${ }^{1,2}$, Laurent Lacaze $^{1,2}$ and Olivier Eiff ${ }^{1,2}$
The present work is dedicated to the study of the swash zone bed evolution at a high temporal and spatial resolution to investigate single-wave to wave-group time scales. The measurements are obtained in a large scale wave flume with a $1 / 15$ sloping beach of well-sorted sand $\left(\mathrm{d}_{50}=250 \mu \mathrm{m}\right)$. The wave regime considered is a random Jonswap spectrum (peak enhancement factor $\gamma=3.3$, significant wave height $\mathrm{H}_{\mathrm{S}}=0.53 \mathrm{~m}$ and peak period $\mathrm{T}_{\mathrm{p}}=4.14 \mathrm{~s}$ ). A stereoscopic technique (Astruc et al., 2012) has been used to measure the sand bed evolution in the swash zone over a $3 \times 2 \mathrm{~m}^{2}$ area. This experiment allows us to capture the swash dynamics and the bottom evolution at the different temporal scales. The results prove the strong correlation between wave forcing and swash zone response over the entire experiment, even if the bottom evolves. At shorter time scales, we can observe the signature of gravity and infragravity waves. We showed that at both time scales, the erosion process exhibits a strong variability in time as accretion and erosion events are observed. The spatial variability of the bottom evolution is stronger at gravity than at infragravity time scales. These results reinforce the now-admitted idea that the mean evolution of the sand bed in the swash zone is the result of several events of a very different nature, which themselves depend on the details of the swash hydrodynamics.
\end{abstract}

Keywords: swash zone; stereoscopic technique; sand bed evolution; gravity and infragravity waves.

\section{INTRODUCTION}

The upper part of the nearshore area, known as the swash zone, is the place of intense sediment transport and very fast morphological changes. It is now admitted that this very specific behavior is due to the very complex and energetic hydrodynamic processes close to the shoreline. In particular the randomness of the incident wave forcing leads to a strong temporal and spatial variability of the hydrosedimentary processes. Finally, it is worth noticing that knowledge of swash dynamics is fundamental to predict the evolution of coastal areas as the swash zone acts as a boundary condition for nearshore hydrodynamic and morphodynamic models at larger scale.

Over the last decade, a special attention has been paid towards the understanding of the swash zone bottom evolution and the corresponding sediment exchanges with the surf zone. These studies show that these quantities are related to the local hydrodynamics and sediment transport in the swash zone, which intrinsically evolve at the wave time scale (Butt and Russell, 2000; Elfrink and Baldock, 2002; Masselink and Puleo, 2006; Puleo and Butt, 2006; Backhtyar et al., 2009). Recently a field study (Turner et al., 2008) has shown that bed-level variations induced by a single swash event may reach an amplitude of the order of $\mathrm{cm}$, which is larger than the mean over experiment duration (several hours). Therefore, long-term beach evolution modeling requires an accurate description of wave time scale processes which remain not fully understood due to both the complexity of the processes and the difficulty of measurements in this area, as for instance the intermittency of the flow.

Instrumentation in this area is still a significant challenge to obtain highly resolved and accurate measurements over a significant spatial extent of the swash area. Even if the strong variability in this zone makes spatio-temporal measurement difficult, some innovative techniques were proposed to carry out these measurements. An acoustic gauge system was used by Turner et al. (2008), to obtain high frequency and non-intrusive measurements of the bed position at some specific locations, with a vertical accuracy of $\pm 1 \mathrm{~mm}$. An extension to spatially-resolved measurements is possible using an optical stereoscopic technique to reconstruct the three-dimensional bottom position. Holland and Holman (1997) proposed an in-situ implementation of the stereoscopic technique in which the foamy runup edge was used as a natural pattern for a scanned beach surface reconstruction. The vertical accuracy of this technique was estimated to be of the order of $2 \mathrm{~cm}$. Another stereoscopic method was developed for large scale laboratory facility which allows an instantaneous measurement of a $3 \times 2 \mathrm{~m} 2$ area in the swash zone (Astruc et al., 2012). This technique which relies on a projected light pattern on the sand surface, proved to have a vertical accuracy of less than $1 \mathrm{~mm}$.

The present work is dedicated to a laboratory study of the swash zone bed evolution under random wave erosive conditions at high temporal and spatial resolution using the latter technique. The purpose is to investigate a range of time scales from single gravity wave to several infragravity waves. The

\footnotetext{
${ }^{1}$ Université de Toulouse; INPT, UPS; IMFT (Institut de Mécanique des Fluides de Toulouse); Allée Camille Soula, F31400 Toulouse, France

${ }^{2}$ CNRS; IMFT; F-31400 Toulouse, France
} 
paper is organized as follows. First, the experimental apparatus and the stereoscopic technique are described. Then, analysis of the spatio-temporal bottom variation at the various time scales is presented. Finally, conclusions are drawn.

\section{LARGE SCALE FACILITY AND WAVE CONDITIONS}

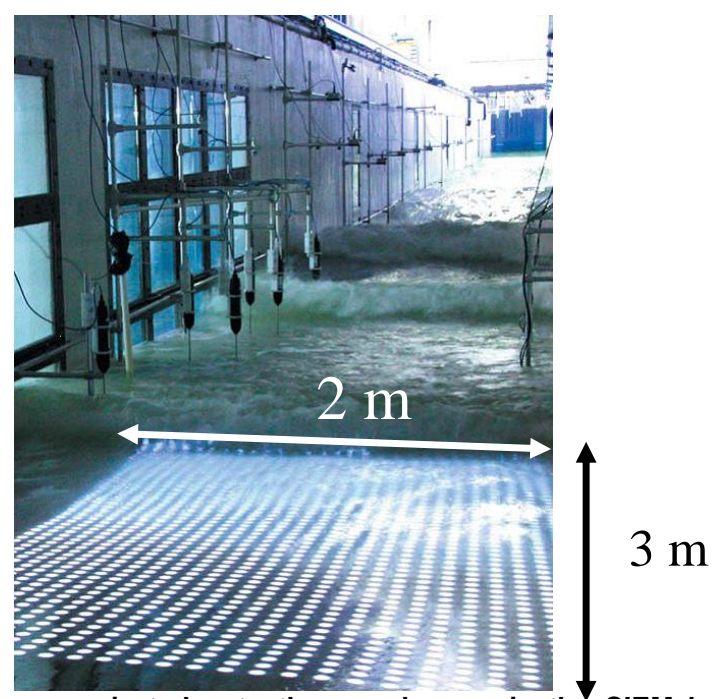

Figure 1. Grid of light dot patterns projected onto the swash zone in the CIEM large-scale wave flume at the UPC (Barcelona).

The measurements have been performed in the CIEM large-scale wave flume (100 $\mathrm{m}$ long and $3 \mathrm{~m}$ wide) at UPC in Barcelona (Fig. 1), within the HYDRALAB III / SANDS project. The initial sand bottom is a $1 / 15$ sloping beach of well-sorted sand $\left(\mathrm{d}_{50}=250 \mu \mathrm{m}\right)$. A forcing with random erosive wave conditions (Jonswap spectrum with peak enhancement factor $\gamma=3.3$, with a significant wave height $\mathrm{H}_{\mathrm{S}}$ $=0.53 \mathrm{~m}$ and a peak period $\mathrm{T}_{\mathrm{p}}=4.14 \mathrm{~s}$ ) is used (Alsina and Cáceres, 2011). The entire experiment consists of 39 time series (TS) of 30 min duration each, which are carried out successively with the same wave forcing. The experiment time $t=0$ at the beginning of the experiment. For a given time series a local time $\mathrm{t}_{\mathrm{s}}$ is used with $\mathrm{t}_{\mathrm{s}} \in[0,30]$ min, and $\mathrm{t}_{\mathrm{s}}=0$ at the beginning of the time series.

The frame of reference has its origin at the shoreline position $(75.42 \mathrm{~m}$ from the wave paddle $)$ and at the middle of the wave flume. $\mathrm{x}$-axis is aligned with the wave flume, $\mathrm{y}$-axis is the transverse direction and $\mathrm{z}$-axis is the vertical direction.

\section{A STEREOSCOPIC TECHNIQUE FOR SAND SURFACE MEASUREMENT}

The stereoscopic technique developed by Astruc et al. (2012) has been used to measure the bed evolution over a $3 \times 2 \mathrm{~m}^{2}$ area in the swash zone (Fig. 1). The general method consists in the reconstruction of 3D surfaces by imaging the scene with two different view sights. In the present case, the sequences of images are acquired by two cameras recording the same area of interest in the swash zone (Fig. 2). The reconstruction of the three-dimensional foreshore surface then requires the matching of identifiable patterns between the two cameras. For this purpose, different methods can be found in the literature, usually based on the inter-correlation of the image pair, allowing the matching of random patterns of the scene. However, in order to obtain a good accuracy of the measurement in the case of the large field considered here, Astruc et al. (2012) preferred to these standard methods a regular grid of circular pattern projected on the swash zone by a light source (Fig. 1 and Fig. 2), each image position being extracted independently. The center position of each dot pattern is first estimated at a pixel scale in two steps, both of them consisting in the extraction of correlation peaks obtained from the image intensity correlation between a reference pattern and the entire image. This estimation is performed in two steps, the reference pattern being first a binary pattern and then an average image pattern (see insets of Figs. 3 (a) and (b)) obtained from the first estimation. A sub-pixel algorithm is finally applied to extract the position of the dot center with an accuracy of the order of 0.05 pix. Taking advantage of the regular grid pattern, the matching between the two images then consists in ordering extracted dot positions. The three-dimensional position of each pattern is then obtained using a triangulation method 
developed by Bouguet (2004) and based on a calibration step performed before each experiment. The calibration procedure used here is explained in Astruc et al. (2012). It can finally be noted that the two cameras are synchronized using an external trigger in order to limit time shifting effects that could affect the accuracy of the technique.

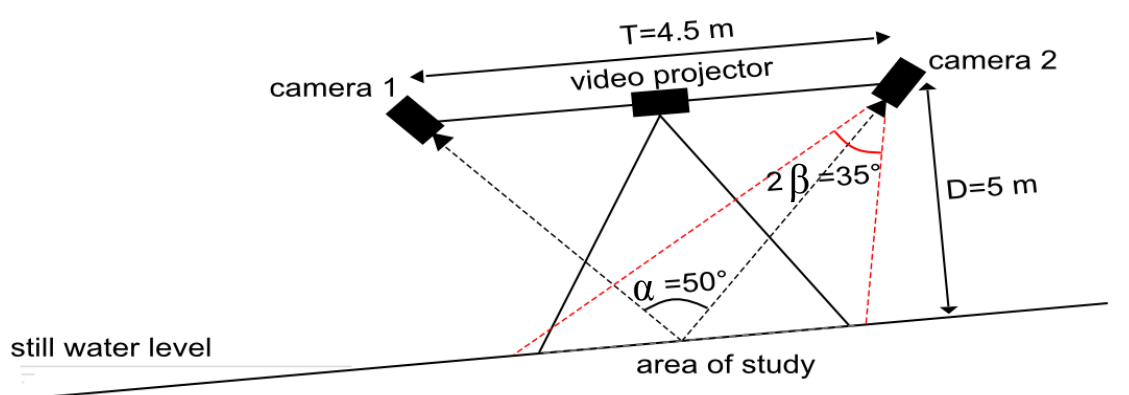

Figure 2. Sketch of the stereovision system set-up (not to scale). Cameras 1 and 2 record the sand-bed in a $3 \times 2 \mathrm{~m}^{2}$ area in the swash zone. Black dashed lines correspond to the optical axes of the cameras, red dashed lines bound the angle of view of the cameras and black lines bound the projection area of the video projector.

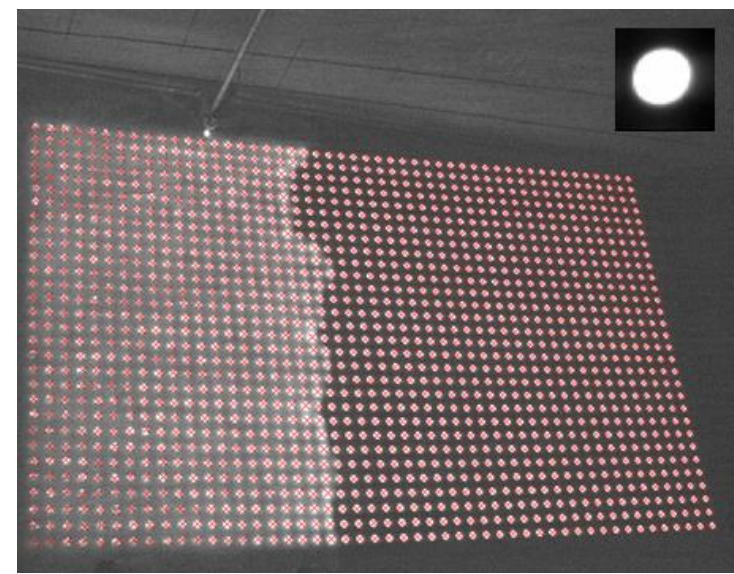

(a)

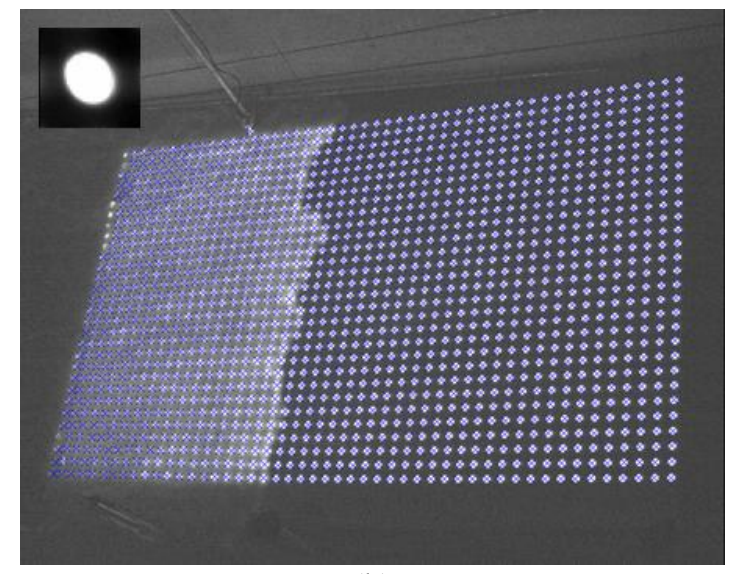

(b)

Figure 3. Position of the dots centers detected by using the reference pattern for camera 1 (a) and camera 2 (b) respectively.

Finally, in order to enhance the accuracy of the stereoscopic technique, the two cameras were synchronized using an external trigger (Figs. 3 (a) and (b)). A case of a completely dry beach was chosen as the reference image. A binary dot pattern of radius similar to the radius of the images of the dots of the illuminated area was defined. A first correlation of the reference image was made with this binary pattern, the local maxima corresponding to a first estimation of the position of the image-dot centers. Then, for each camera independently, in order to enhance the accuracy of the detection, the following method was used. A reference pattern (Figs. 3 (a) and (b)) was obtained by calculating the average pattern of the detected dots obtained from the first correlation. The correlation of each image with the reference pattern was done, allowing to detect each dot center. Taking advantage of the regular grid pattern, the dots were ordered for pairing between the two cameras. Finally, the surface level $\mathrm{h}(\mathrm{x}, \mathrm{y}, \mathrm{t})$ was reconstructed from the dots pairing (Fig. 4), using a triangulation method. Such a technique requires a step of calibration to estimate the optical properties of the cameras system.

During the experiments, each time series was sampled at $\Delta \mathrm{f}_{\mathrm{S}}=5 \mathrm{~Hz}$. 
The estimation of the accuracy of the stereoscopic technique is not trivial since the error is inherent to the different steps of the method. However, Benetazzo (2006) proposed a theoretical estimation of the accuracy, which shows to be maximum in the direction perpendicular to the axis joining the two cameras and lying in the plane defined by the two lines of sight. Here, this direction is nearly the same as the vertical axis. The theoretical estimation of the accuracy in the vertical direction then reads

$$
e r r_{Z}=\frac{D^{2}}{2 T N} \frac{\sin (2 \beta)}{\cos (\beta+\alpha)^{2}}
$$

where $\mathrm{D}$ and $\mathrm{T}$ are the distances from the baseline and between the two cameras, respectively, and $\alpha$ is the angle between the cameras' line of sight (Fig. 2). $\mathrm{N}$ is the number of pixels in one direction of the sensor and $\beta$ corresponds to half the angle of view of the cameras. The sub-pixel algorithm used gives an error on the estimation of the image dot positions of 0.05 pix in the vertical direction. Then, considering the sub-pixel algorithm used, $\mathrm{N}$ was replaced by $\mathrm{Neff}=\mathrm{N} / 0.05$ to evaluate the maximum accuracy. In the present case, $\left(\mathrm{D}=5 \mathrm{~m}, \mathrm{~T}=4.5 \mathrm{~m}, \alpha=50^{\circ}, \beta=17.5^{\circ}\right.$ and $\left.\mathrm{Neff}=\mathrm{N} / 0.05=2048 / 0.05\right)$, the theoretical error obtained is $\operatorname{err}_{\mathrm{Z}} \sim 100 \mu \mathrm{m}$ (Eq. 1).

From experimental analysis, a vertical accuracy of $600 \mu \mathrm{m}$ is obtained as explained in Astruc et al. (2012). The difference between theoretical and measured accuracy is attributed to several sources of error such as the vibrations of the system, the uncertainty of the form of the projected light dots on a rough sand surface or the light beam fluctuation. At that level of accuracy, the variations with an amplitude of about $1 \mathrm{~mm}$, can be measured.

\section{SAND REGION RECOGNITION}

The stereoscopic technique allows to measure the temporal evolution of the measured surface, $\mathrm{h}(\mathrm{x}, \mathrm{y}, \mathrm{t})$, in the swash zone. However, as the swash zone is alternatively covered and uncovered by waves, investigation of its evolution now requires to distinguish the sand surface from the water surface (Fig. 4). A criterion was proposed by Turner et al. (2008) to distinguish the state of the measured surface, the sand surface being defined by $|\partial \mathrm{h} / \partial \mathrm{t}|<\varepsilon$ and the water surface by $|\partial \mathrm{h} / \partial \mathrm{t}| \geq \varepsilon$, with $\varepsilon=0.05$ $\mathrm{cm} / \mathrm{s}$. This criterion is based on the fact that a sand region is characterized by a steady surface position. The above-mentioned threshold parameter $\varepsilon=0.05 \mathrm{~cm} / \mathrm{s}$ is dimensional and adapted to the specific case of the field study carried out by Turner et al. (2008). Nevertheless, this procedure is used here and extended to the case of continuous spatial measurements.

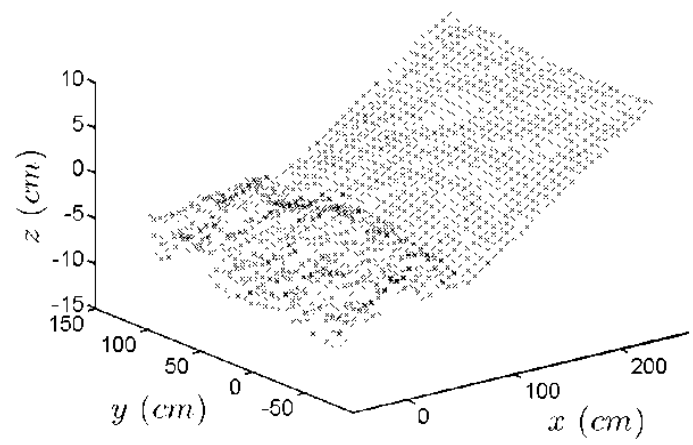

Figure 4. 3D reconstruction of the surface level $z=h(x, y, t)$ in the swash zone at $t_{s}=897 \mathrm{~s}$ of $\mathrm{TS}=10$. 


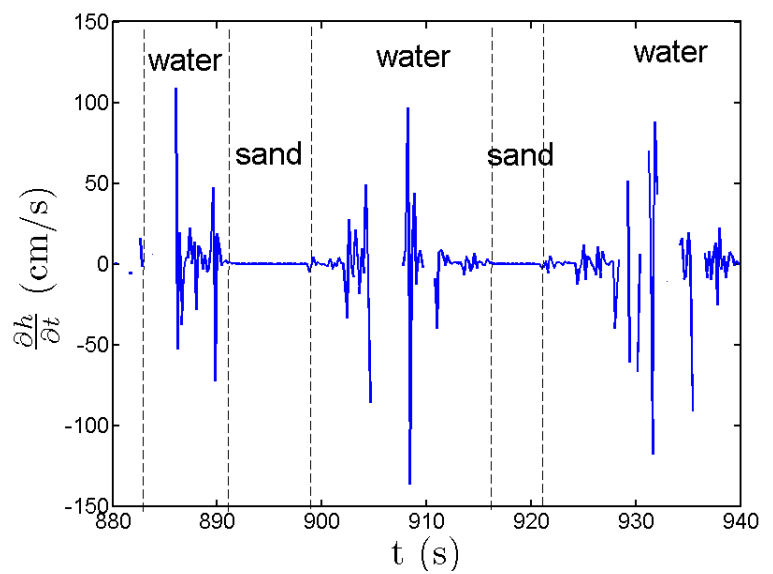

Figure 5. Temporal evolution of the time rate of change of the measured surface elevation $h(x, y)$ during TS = 10 at $x=232.7 \mathrm{~cm}$ and $y=15 \mathrm{~cm}$.

At a fixed position, the time evolution of the height, $\partial \mathrm{h} / \partial \mathrm{t}$, is shown to be small in the sand region but not zero, the minimum value being correlated to the error of the stereoscopic technique (Fig. 5). On the other hand, the water region is associated with a significant variability of $\partial \mathrm{h} / \partial \mathrm{t}$. As threshold parameter $\varepsilon$, defined above, is a dimensional parameter, its value has been evaluated for the specific experimental parameters used here. In particular, given the accuracy $\operatorname{err}_{\mathrm{Z}}=600 \mu \mathrm{m}$ of the stereoscopic technique and the sampling period $\Delta \mathrm{t}_{\mathrm{S}}=0.2 \mathrm{~s}\left(\Delta \mathrm{t}_{\mathrm{S}}=1 / \Delta \mathrm{f}_{\mathrm{S}}\right.$, with $\Delta \mathrm{f}_{\mathrm{S}}=5 \mathrm{~Hz}$ the sampling frequency), a lower limit for $\varepsilon$ can be estimated:

$$
\varepsilon \geq \frac{e r r_{Z}}{\Delta t_{S}}=\frac{e r r_{Z}}{1 / \Delta f_{S}} \sim 0.3 \mathrm{~cm} / \mathrm{s}
$$

The lower limit (Eq. 2) corresponds to the limit for which the signal cannot be distinguish from the noise. In order to extract a maximum information in the sands region, a slightly higher value $\varepsilon=0.4$ $\mathrm{cm} / \mathrm{s}$ is chosen.

(a)

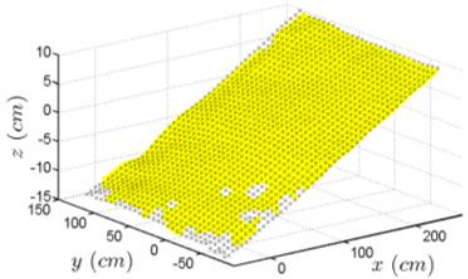

(d)

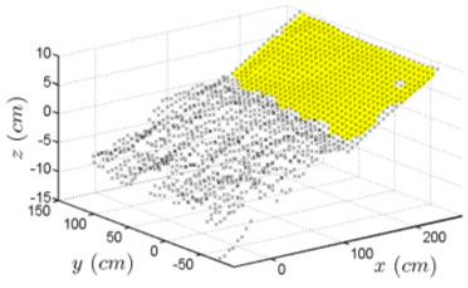

(b)

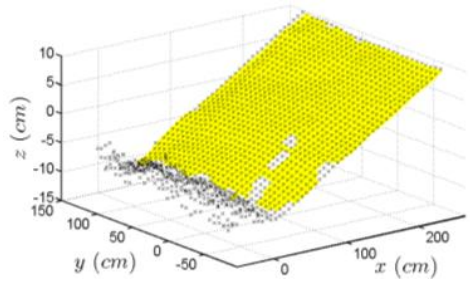

(e)

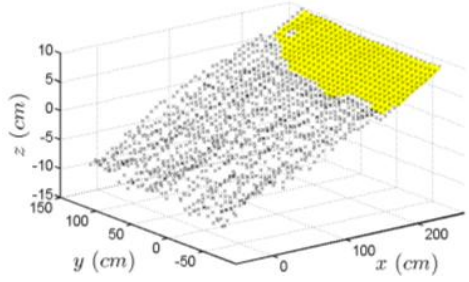

(c)

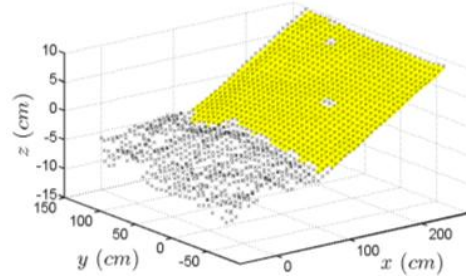

(f)

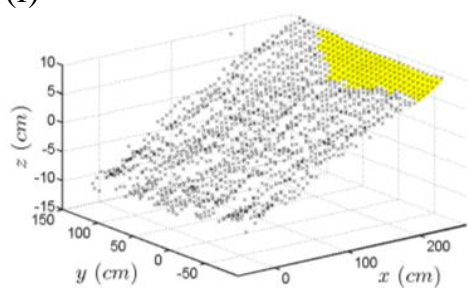

Figure 6. Time evolution (from (a) to (f)) of a run-up event and detection of sand $(|\partial \mathrm{h} / \partial \mathrm{t}|<0.4$, yellow) and water $(|\partial \mathrm{h} / \partial \mathrm{t}| \geq 0.4)$ regions in the swash zone.

Fig. 6 shows the time evolution of a run-up event. As observed in this figure, $\varepsilon=0.4 \mathrm{~cm} / \mathrm{s}$ therefore allows to accurately distinguish the sand region from the water region and to properly capture the time 
evolution of the waterfront position. The less energetic the waterfront is, the more delicate its position detection is. In the case of a run-up event, the propagation of the front is well defined. It is thus possible to quantitatively analyze the front evolution. On the other hand, during a backwash event, the phenomena involved are more complex and the shoreline detection more difficult to follow.

\section{ANALYSIS OF BOTTOM EVOLUTION}

\section{Swash dynamics at long time scale}

As mentioned previously, the experiments have been carried out under erosive conditions. Fig. 7 shows the temporal evolution of cross-shore profiles of the sand bed level $h(x, y)$ averaged along the transverse direction $(<h\rangle_{y}(x, t)=\frac{1}{L_{y}} \int_{y} h(x, y, t) d y$, with $\mathrm{L}_{\mathrm{y}}$ the width of the sand surface at this cross-shore position). As expected from the experimental wave conditions used, a global erosion of the beach profile is observed in the measurement area.

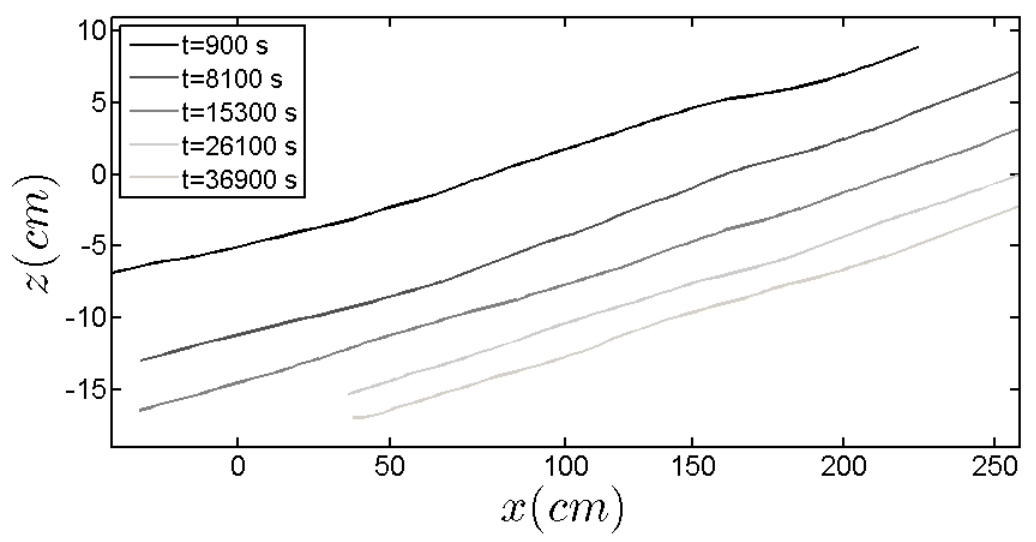

Figure 7. Cross-shore profiles $z=\langle h\rangle_{y}(x, t)$ of the sand bed level at different times. $\langle h\rangle_{y}(x, t)$ is the average value of $h(x, y, t)$ along the transverse direction (adapted from Fig.12, Astruc et al., 2012).

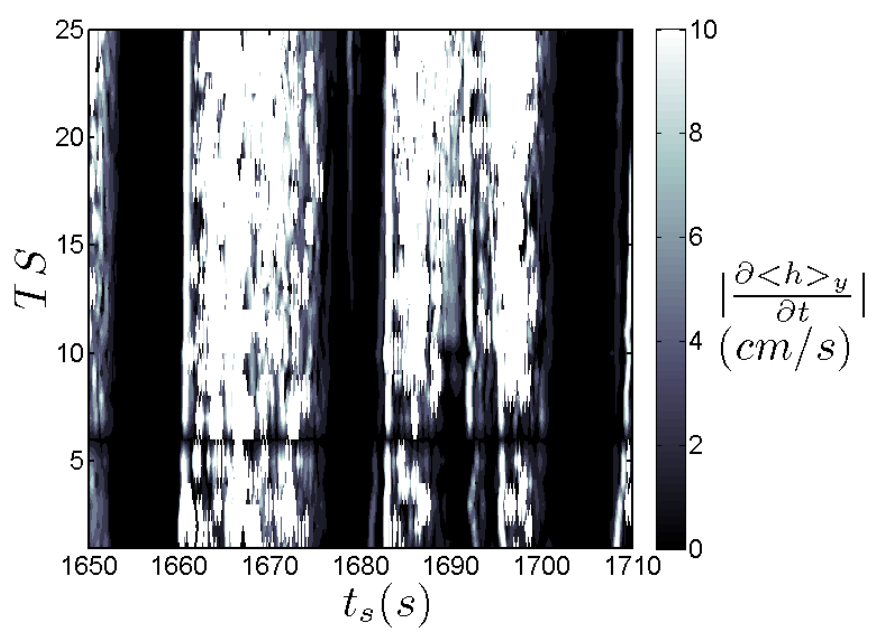

Figure 8. Temporal-temporal diagram of $|\partial<h>y / \partial t|$ at $x=158 \mathrm{~cm}$. The horizontal axis represents the time evolution, while the vertical axis corresponds to the different TS. The same forcing is imposed by the wave paddle for each horizontal line (TS). 
Fig. 8 shows the evolution of $|\partial<\mathrm{h}>\mathrm{y} / \partial \mathrm{t}|$, at a given cross-shore position $\mathrm{x}$, in the ( $\left.\mathrm{t}_{\mathrm{s}}-\mathrm{TS}\right)$ plane. Dark areas, i.e. low $\partial<\mathrm{h}>\mathrm{y} / \partial \mathrm{t}$ are the signature of emerged sand while clear areas correspond to water. One can observe that at least for this time interval, the run-up/backwash dynamics is nearly the same in every TS. A slight drift of the dry areas is observed which is due to the overall erosion of the beach. It means that the hydrodynamics forcing remains almost unchanged within time series, despite the significant sand surface evolution between each TS.

\section{Swash dynamics at short time scales}

Fig. 9 shows the temporal evolution of the limit between water and sand as well as the sand bed level during a $60 \mathrm{~s}$ interval. The successive swash and backwash events are detected although the extension of the measurement does not cover the upper part of the swash zone. Two time scales can be depicted in the wave dynamics in the swash zone: (i) a short time scale $\left(\mathrm{Tg}_{1}=\mathrm{Tg}_{2}=4 \mathrm{~s}\right)$ corresponding to the peak period of the Jonswap spectrum, signature of the gravity wave forcing, (ii) an infragravity wave time scale $\left(\mathrm{Ti}_{1}=\mathrm{Ti}_{2}=20 \mathrm{~s}\right.$ and $\left.\mathrm{Ti}_{3}=12 \mathrm{~s}\right)$ which corresponds either to seiching modes of the wave flume or to surf beat generated by wave groups. Sand surface evolution is therefore analyzed at these two time scales in order to highlight their relative influence on the bottom evolution.

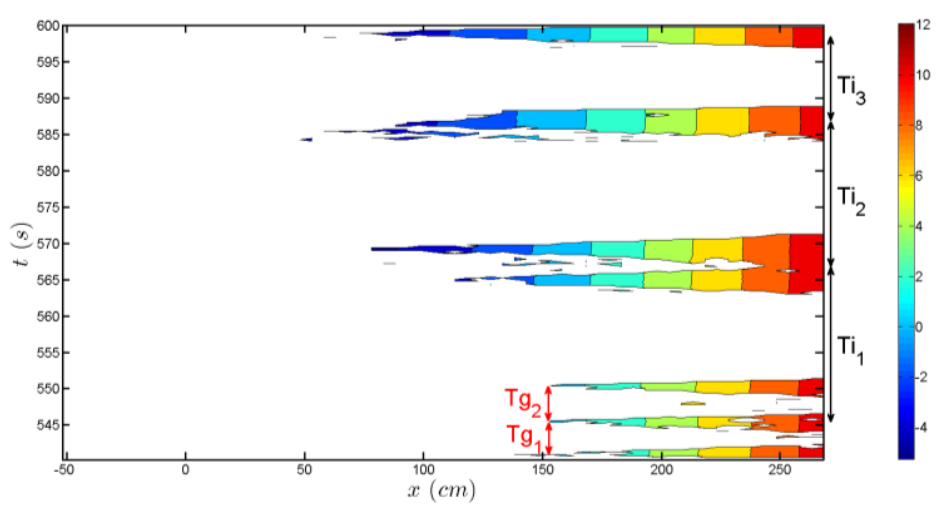

Figure 9. Spatio-temporal evolution of the sand bed level (colored areas), at $\mathrm{y}=-\mathbf{5 0} \mathrm{cm}$, during $\mathrm{TS} 07$. $\mathrm{Tg}_{1}$ and $\mathrm{Tg}_{2}$ are the period of two successive gravity waves whereas $\mathrm{Ti}_{1}, \mathrm{Ti}_{2}$ and $\mathrm{Ti}_{3}$ are the period of three successive infragravity waves.

(a)

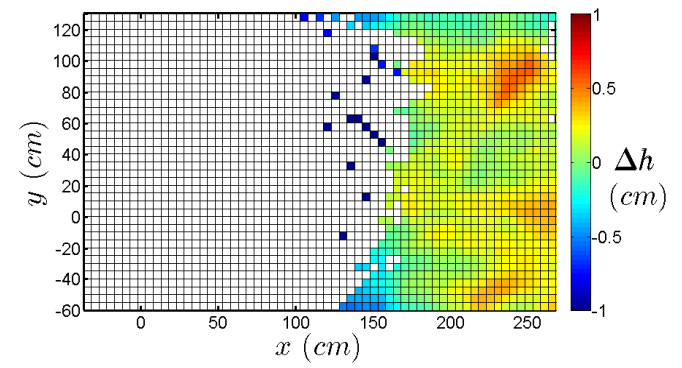

(b)

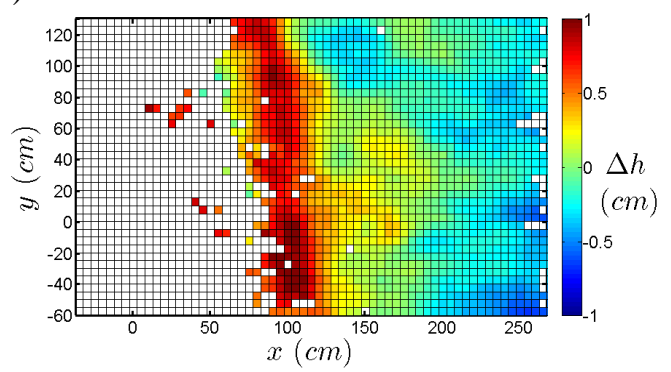

(c)

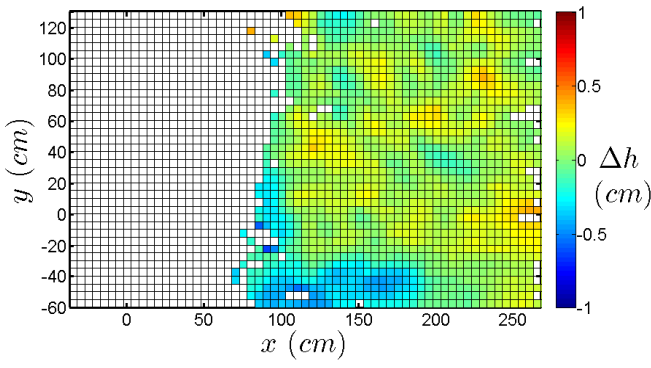

Figure 10. Sand surface evolution resulting from three successive infragravity waves of periods $\mathrm{Ti}_{1}(\mathrm{a}), \mathrm{Ti}_{2}$ (b) and $\mathrm{Ti}_{3}(\mathrm{c})$. 
Figs. $10(a),(b)$ and (c) show the sand surface evolution $\Delta h(x, y)=\left\{\hbar_{a}(x, y)-\hbar_{b}(x, y)\right\}$, induced by three successive infragravity waves of respective period $\mathrm{Ti}_{1}, \mathrm{Ti}_{2}$ and $\mathrm{Ti}_{3}$ where $\hbar$ is the mean temporal value of $\mathrm{h}$ in-between two infragravity waves. Subscripts a and b corresponds to "after" and "before" a given wave event. At this time scale, variations of the sand bed of about $1 \mathrm{~cm}$ are measured. Beach erosion phenomena may occur, for instance on the upper part of the measured area (Fig. 10 (b)), as well as accretion phenomena (Figs.10 (a) and (c)). These observations show that the bottom evolution is not a monotonic process despite the long term erosion. Moreover the spatial structure of the bottom evolution is almost independent of the cross-shore direction (Figs.10 (a) and (b)).

(a)

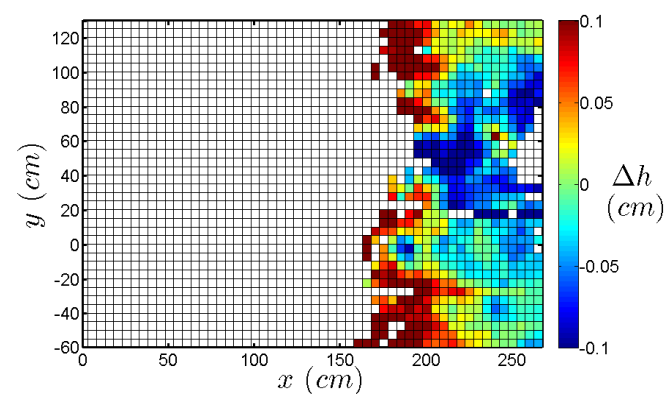

(b)

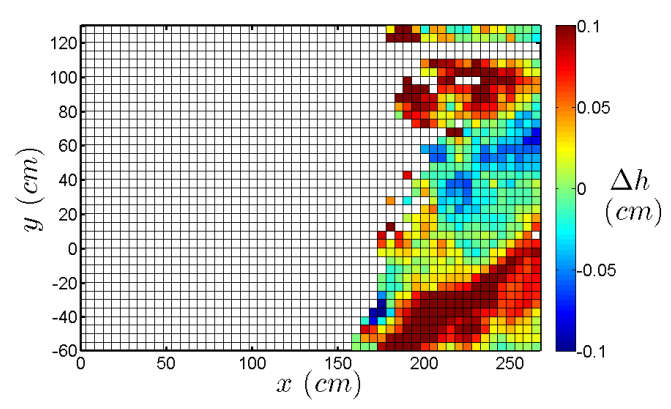

Figure 11. Sand surface evolution resulting from two successive gravity waves of periods $\operatorname{Tg}_{1}(a)$ and $\operatorname{Tg}_{2}(b)$.

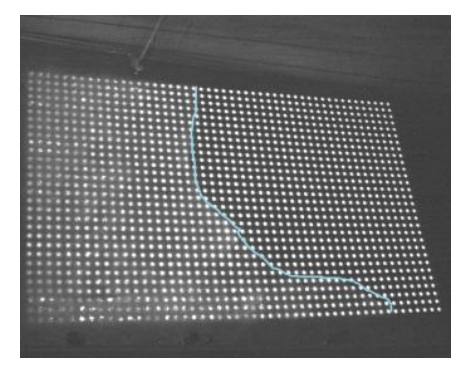

Figure 12. An example of three-dimensional gravity wave propagation (waterfront is painted in blue).

Figs. 11 (a) and (b) show the sand surface variation for two successive gravity waves of respective period $\mathrm{Tg}_{1}$ and $\mathrm{Tg}_{2}$ which is of the order of $2 \mathrm{~mm}$ (Fig. 9). Even if the variations at this time scale are smaller than those obtained at the infragravity wave time scale, a strong temporal variability between wave events is also observed. However, the spatial evolution resulting from the gravity waves is strongly three-dimensional unlike what is observed for infragravity waves. This pattern of accretion and erosion regions might depends on the instantaneous wave forcing as gravity waves proved to be threedimensional in this experiment (Fig. 12).

\section{CONCLUSION}

A stereoscopic technique for sand surface measurement which is well-resolved in time and space and $600 \mu \mathrm{m}$ accurate has been used. This method provides the reconstruction of the entire threedimensional surface over the measured area and a criterion has been defined to distinguish water from sand surface.

This technique has been used to investigate the bottom evolution of a swash zone under erosive conditions in a large scale facility. At long time scale, the global erosion of the beach profile has been measured. At shorter time scales, an analysis of the influence of gravity and infragravity waves on the sand surface evolution in the swash zone has been performed. At both time scales, a strong variability of the bottom evolution (accretion and erosion) is observed, even if the resulting global evolution is of erosive nature. 


\section{ACKNOWLEDGMENTS}

The first author is supported by a scholarship intended for $\mathrm{PhD}$ students funded by the

D'CA DGA (Direction Générale de l'Armement).

The present work has been funded by the EC Hydralab-III SANDS project (contract number: 022441) (RII3) and the EC Hydralab-IV WISE Project (contract number: 261520).

\section{REFERENCES}

Alsina, J.M. and I. Cáceres. 2011. Sediment suspension events in the inner surf and swash zone. Measurements in large-scale and high-energy wave conditions. Coastal Engineering, 58, 657-670.

Astruc, D., S. Cazin, E. Cid, O. Eiff, L. Lacaze, R. Robin, F. Toublanc and I. Caceres. 2012. A stereoscopic method for rapid monitoring of the spatio-temporal evolution of the sand-bed elevation in the swash zone, Coastal Engineering, 60, 657-670.

Bakhtyar, R., D.A., Barry, L., Li, D.S., Jeng and A., Yeganeh-Bakhtiary. 2009. Modeling the sediment transport in the swash zone: A review. Ocean Engineering, 36, 767-783.

Benetazzo, A. 2006. Measurements of short water waves using stereo matched image sequences. Coastal Engineering, 53, 1013-1032.

Bouguet, J.Y., 2004. Camera calibration toolbox for matlab. http://www.vision.caltech.edu/bouguetj/calib_doc/.

Butt, T. and P. Russel. 2000. Hydrodynamics and cross-shore sediment transport in the swash-zone of natural beaches: a review. Journal of Coastal Research, 16, 255-268.

Elfrink, B. and T. Baldock. 2002. Hydrodynamics and sediment transport in the swash zone: a review and perspectives. Coastal Engineering, 45,149-167.

Holland K.T. and R.A. Holman. 1997. Video estimation of foreshore topography using trinocular stereo. Journal of Coastal Research, 13, 81-87.

Masselink, G. and J. Puleo. 2006. Swash-zone morphodynamics. Continental Shelf Research, 26, 661680.

Puleo, J.A. and T. Butt. 2006. The first international workshop on swash-zone processes. Continental Shelf Research, 26 (5), 556-560.

Turner, I.L., P.E. Russell and T. Butt. 2008. Measurement of wave-by-wave bed-levels in the swash zone. Coastal Engineering, 55, 1237-1242. 